Published as: Herman Kruger, Walter W. Focke, Washington Mhike, Albertus Taute, Albert Roberson and Osei Ofosu. Cone calorimeter study of polyethylene flame retarded with expandable graphite and intumescent fire retardant additives. Journal of Fire Sciences. 2014, Vol. 32(6) 498-517 http://jfs.sagepub.com/content/32/6/498

\title{
Cone calorimeter study of polyethylene flame retarded with expandable graphite and intumescent fire retardant additives
}

Hermanus Joachim Kruger ${ }^{1}$, Walter Wilhelm Focke ${ }^{1, *}$, Washington Mhike ${ }^{1}$, Albertus Taute ${ }^{1}$, Albert Roberson ${ }^{1}$ and Osei Ofosu ${ }^{2}$

${ }^{1}$ SARChI Chair in Carbon Technology and Materials, Institute of Applied Materials, Department of Chemical Engineering, University of Pretoria, Private Bag X20, Hatfield 0028, South Africa

${ }^{2}$ CSIR Materials Science and Manufacturing, PO Box 1124, Port Elizabeth 6000, South Africa

\begin{abstract}
Polyethylene was flame retarded with an intumescent flame retardant at $27 \mathrm{wt} . \%$ and expandable graphite at $10 \mathrm{wt} . \%$ either on its own or in combination with $10 \mathrm{wt} . \%$ or $20 \mathrm{wt} . \%$ of the intumescent. Two grades of each flame retardant type were used. They differed primarily with respect to the onset temperature for exfoliation (commercially sourced expandable graphite types) or decomposition (intumescents). The latter were the highdecomposition-onset-temperature intumescent 3,5-diaminobenzoic acid phosphate and the commercially available low-decomposition-onset-temperature ethylenediamine phosphate. The fire performance of pressed sheets with a nominal thickness of $3.2 \mathrm{~mm}$ was tested in a cone calorimeter at a radiant flux of $35 \mathrm{~kW} \mathrm{~m}^{-2}$. The best char yields were obtained with compositions containing 3,5-diaminobenzoic acid phosphate. Despite this, the best fire overall performance was realized using ethylenediamine phosphate, together with the lowexfoliation-onset-temperature expandable graphite. Formulations based on this intumescent compound ignited later, reached the peak heat release rate earlier, and also burned longer irrespective of the expandable graphite grade used. This can be attributed to the formation, at the burning surface, of a more cohesive char with better thermal and mass transfer barrier properties. This explains why compositions based on ethylenediamine phosphate as intumescent outperformed those containing 3,5-diaminobenzoic acid phosphate in terms of the peak heat release rate and other important fire indices.
\end{abstract}

\section{Keywords}

Expandable graphite; exfoliation; intumescent flame retardant; thermal analysis; cone calorimeter 


\section{Introduction}

Polyethylene is used to fabricate melded goods such as battery boxes and air ventilation ducting, as well as extruded products such as pipes and cable sheathing. These products are used extensively in deep-level underground mining applications. Polyethylene has a high heat of combustion and a low propensity for char formation. (1) As a result, these products present a potential fire hazard which is of particular concern in confined space mining applications. It is therefore necessary to flame retard polyethylene products with suitable additives for critical applications. A wide range of effective flame retardants are available. $(1,2)$ Recent studies have highlighted the utility of expandable graphite, intumescent flame retardants and their synergistic combinations which improve the fire behaviour of polyethylene. $(1,3-8)$ Intumescent additives swell when exposed to fire or heat. They form a carbonaceous foam residue on the surface that acts as a heat insulator and a physical barrier to the transport of oxygen and pyrolysis products. $(2,9-11)$

Expandable graphite (EG) is a partially oxidized, intercalated form of graphite. It contains intercalated guest species (e.g. sulfuric acid anions) in between the stacked graphene layers. $(12,13)$ A key property of expandable graphite is its tendency to exfoliate explosively, i.e. to expand rapidly in a worm-like manner when heated to high temperatures. (14-16) When this occurs at an upward facing surface of a polymer, a loose cover of "fluffy" vermicular graphite is deposited. This provides a protective barrier similar to that generated by conventional intumescent additives. However, unlike the foam coating generated by conventional intumescent flame retardants, this cover is weakly bonded to the polymer surface and there is no cohesion between adjacent EG "worms". This leads to poor performance when the fire is associated with strong convection currents or when a sample is exposed to a flame from below. 
Cone calorimetry is a modern method for measuring the ignition time, heat release rate, combustion products and other flammability characteristics of polymer samples. This fire testing method determines the transient heat release rate by measuring transient oxygen consumption rate in the exhaust gases. According to Babrauskas (17) the heat release rate is the most important single variable in characterizing the "flammability" of products and thus the fire hazard they may pose. Among the more widely used polymers, polyethylene features the highest heat release capacity and the highest heat release rate in cone calorimeter tests. (2) According to Han and Zhao (8) and Xie and Qu (4) better fire properties are possible with combinations of EG and other intumescent flame retardants. However, only a few such combinations have been explored to date. Therefore this contribution considered two expandable graphite grades and two intumescent flame retardants as additives for polyethylene. The two grades in each category differed primarily with respect to their decomposition onset temperatures. The fire performance of these additives, on their own and in selected combinations, was studied using cone calorimeter fire testing. A key objective was to determine whether adding an intumescent flame retardant to an EG flame retarded compound can improve cohesion of the exfoliated graphite layer to the polymer surface and cohesion between individual EG "worms".

\section{Experimental}

\section{Materials}

Sasol Polymers supplied the low density polyethylene in powder and pellet form. It was injection moulding grade LT019 with density $0.919 \mathrm{~g} \mathrm{~cm}^{-3}$ and MFI $20.5 \mathrm{~g} / 10 \mathrm{~min} @$ $190^{\circ} \mathrm{C} / 2.16 \mathrm{~kg}$. Carbon black grade N660 was sourced from Ferro Industrial Products. The expandable graphite grades ES170 300A (with a high expansion onset temperature) and ES250 B5 (low expansion onset temperature) were sourced from Qingdao Kropfmuehl, 
China. The $\mathrm{d}_{10}, \mathrm{~d}_{50}$, and $\mathrm{d}_{90}$ particle sizes of these two grades were $306 \mu \mathrm{m}, 517 \mu \mathrm{m}, 803 \mu \mathrm{m}$ and $313 \mu \mathrm{m}, 533 \mu \mathrm{m}$ and $807 \mu \mathrm{m}$ respectively (Mastersizer 2000, Malvern Instruments, Malvern, UK). The densities were $2.08 \pm 0.01$ and $2.23 \pm 0.01 \mathrm{~g} \mathrm{~cm}^{-3}$ respectively. The surface area of ES170 300A, in the pre-expanded form, was $0.66 \mathrm{~m}^{2} \mathrm{~g}^{-1}$ (Nova 1000e BET in $\mathrm{N}_{2}$ at $77 \mathrm{~K}$ ). The surface area of the other grade could not be determined by BET as it started to exfoliate when measurement was attempted.

The phosphate salt of 3,5-diaminobenzoic acid (DABAP) was synthesized using the procedure previously described. (18) Ethylenediamine phosphate (EDAP) is available for commercial scale use (from Thor in the US and UK, Krems Chemie (Austria), Westman Chemical (India), and also from Chinese manufacturers. However, for the present study the ethylenediamine phosphate was synthesized as follows: a quantity of $420.7 \mathrm{~g}$ ethylenediamine was weighed into a $5 \mathrm{~L}$ beaker. This beaker was placed in $1.5 \mathrm{~kg}$ of crushed ice. Next a total of $807 \mathrm{~g} 85 \%$ technical phosphoric acid was added drop wise, stirring continuously. The precipitated crystals were recovered by vacuum filtration. They were washed once with cold water and then with acetone and left to dry under ambient conditions. The yield was $0.98 \mathrm{~kg}$ EDAP $(88.6 \%)$.

\section{Preparation of the polyethylene compounds}

Polyethylene compounds containing expandable graphite and/or intumescent flame retardant were compounded on a $28 \mathrm{~mm}$ co-rotating intermeshing twin screw laboratory extruder (L/D $=16)$ at a screw speed of 140-220 rpm. The extruder screw design comprised intermeshing kneader elements with a forward transport action. The four extrusion processing stage temperatures, feed to die, were set at $120{ }^{\circ} \mathrm{C}, 175^{\circ} \mathrm{C}, 175^{\circ} \mathrm{C}$ and $180{ }^{\circ} \mathrm{C}$ respectively. The extruded strands were granulated and the pellets were air-dried. A polyethylene compound containing 5 wt.\% carbon black (N660) was prepared in a similar way. This compound was 
used as the reference sample for cone calorimeter testing. The compounds containing 27 wt.\% intumescent additives (EDAP or DABAP) also contained 5 wt.\% carbon black. This maintained a consistent range of dark product sheets as delivered for all expandable graphite containing compounds. This was done to ensure comparable absorption of infrared radiation during cone calorimeter testing.

Test specimens for cone calorimeter testing were prepared by pressing the pellets into flat sheets in a hot press set at $180{ }^{\circ} \mathrm{C}$. These sheets were prepared at sheet dimensions of 100 $\mathrm{mm} \times 100 \mathrm{~mm} \times 3.2 \pm 0.1 \mathrm{~mm}$.

\section{Characterization and analysis}

Scanning electron microscopy. SEM images were obtained using an ultrahigh resolution field emission SEM (HR FEGSEM Zeiss Ultra Plus 55) with an InLens detector at acceleration voltages of as low as $1 \mathrm{kV}$ to ensure maximum resolution of surface detail. No electro-conductive coating was applied on the graphite particles.

SEM micrographs of the temperature driven dynamic expandable graphite exfoliation processes were also obtained using a scanning electron microscope (FEI QUANTA 200 ESEM) fitted with a heating stage. The graphite flakes were placed inside a crucible and mounted in the heating stage. They were viewed at 200x magnification. The pressure was 0.5 $\mathrm{kPa}$, voltage $20 \mathrm{kV}$, spot size 6-7 and a working distance of $16-20 \mathrm{~mm}$. Temperature was ramped at $20{ }^{\circ} \mathrm{C} \min ^{-1}$.

Thermal analysis. Thermogravimetric analysis (TGA) was performed using the dynamic temperature scan method. Two different instruments, a TA Instruments SDT Q600 and a Mettler Toledo TGA 850e instrument, were employed. Typically about 10 - $15 \mathrm{mg}$ of sample was placed in an open $50 \mu \mathrm{L}$ alumina pan. Sample size was reduced to below $5 \mathrm{mg}$ for 
intumescent materials such as expandable graphite which were placed in $150 \mu \mathrm{m}$ alumina sample holders covered with lids (pin hole) to ensure containment of solids. Temperature was scanned from below $50{ }^{\circ} \mathrm{C}$ to $900{ }^{\circ} \mathrm{C}$ at a scan rate of $10{ }^{\circ} \mathrm{C} \mathrm{min}^{-1}$ with gas (nitrogen or air)

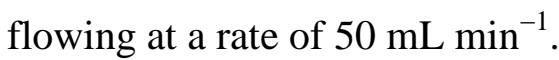

Thermal expansion measurements were conducted on a TA instruments Q400 Thermo Mechanical Analyzer. Sufficient expandable graphite powder was placed in an alumina sample pan such that the bed height was between $35 \mu \mathrm{m}$ and $40 \mu \mathrm{m}$. The flake expansion behaviour was measured with a flat-tipped standard expansion probe using an applied force of $0.005 \mathrm{~N}$. The temperature was scanned from $30{ }^{\circ} \mathrm{C}$ to $600{ }^{\circ} \mathrm{C}$ at a scan rate of $10{ }^{\circ} \mathrm{C} \mathrm{min}{ }^{-1}$ in a nitrogen atmosphere. The expansion relative to the original powder bed height was reported.

Cone calorimeter flammability testing. The ISO 5660-1 standard was followed in performing the cone calorimeter tests using a Fire Testing Technology Dual Cone Calorimeter. Three specimens of each composition were tested and average values are reported. The sheet dimensions were $100 \mathrm{~mm} \times 100 \mathrm{~mm} \times 3.2 \mathrm{~mm}$. They were placed horizontally on aluminium foil and exposed perpendicularly from above to an external heat flux of $35 \mathrm{~kW} \mathrm{~m}{ }^{-2}$.

\section{Results and Discussion}

\section{Characterization}

A comprehensive characterization of the expandable graphite (EG) samples was previously reported. (19) These commercial additives were fabricated by treating natural graphite flakes with oxidants such as nitric acid and potassium permanganate in the presence of sulfuric acid. 
Elemental analysis revealed that the low onset temperature EG (ES250) and the high temperature onset EG (ES170) contained $3.03 \mathrm{wt} . \%$ and $2.27 \mathrm{wt} . \%$ sulfur respectively. The expansion onset temperatures, determined by thermomechanical analysis, were ca. $225^{\circ} \mathrm{C}$ and $300{ }^{\circ} \mathrm{C}$ respectively. Both samples released a mixture of carbon dioxide, carbon monoxide and sulfur dioxide during the exfoliation process. (19)

The SEM micrograph in Figure 1A shows the morphology of the EDAP powder particles. The flake-like morphology of the DABAP crystals is shown in Figure 1B. The expandable graphite particles also had a flake-like nature but the flakes were much larger. (19) Figure 2 shows micrographs of the expanded graphite samples taken in the ESEM. Both samples yielded vermicular residues. The expansion of the low temperature EG resulted in "worms" with a fairly regular cross-section. However, those derived from the high temperature EG were highly irregular in shape. According to the manufacturer, the volume expansion of the low and high temperature EG's were at least $250 \mathrm{~mL} \mathrm{~g}^{-1}$ and $170 \mathrm{~mL} \mathrm{~g}^{-1}$ respectively.

\section{Thermal analysis}

The key property of expandable graphite in fire retardant applications is the ability to exfoliate when exposed to high heat. Figure 3 shows the TMA expansion traces obtained in $\mathrm{N}_{2}$ and the TGA mass loss curves obtained in air for the expandable graphite samples. Apart from a minor mass loss associated with a moisture content of ca. $1 \%$, the mass loss for the high exfoliation onset temperature EG (ES170) occurred in two steps. The first corresponds to the gas released during the exfoliation event. It commenced at ca. $280{ }^{\circ} \mathrm{C}$ and reached a peak mass loss rate at ca. $310^{\circ} \mathrm{C}$. The mass loss associated with the exfoliation reached ca. 
$10 \%$ at $600{ }^{\circ} \mathrm{C}$. The second mass loss event corresponds to the oxidation of graphite residue. Less than $6 \%$ of the graphite sample remained at $900{ }^{\circ} \mathrm{C}$.

The low exfoliation onset temperature EG (ES250) showed four mass loss steps. There was a minor mass loss below $150{ }^{\circ} \mathrm{C}$ indicating a moisture loss of ca. $0.5 \%$. This was followed by a second mass loss event that started at $210{ }^{\circ} \mathrm{C}$ and reached a peak mass loss rate at $226{ }^{\circ} \mathrm{C}$ and resulted in an additional mass loss of $4.5 \%$ (total mass loss of 5\%). The TMA traces indicated that this second mass loss event was associated with the expansion of the EG. The third mass loss event commenced at $361{ }^{\circ} \mathrm{C}$ and peaked at $408{ }^{\circ} \mathrm{C}$ resulting in a further mass loss of $11 \%$ (total mass loss of $16 \%$ ) by $600{ }^{\circ} \mathrm{C}$. The TMA trace indicates that this mass loss was connected with a secondary gas release that ultimately led to the full exfoliation of the graphite. The final step corresponded to oxidation of the graphite residue and a similar char residue remained at $900{ }^{\circ} \mathrm{C}$.

In summary, the exfoliation onset temperatures were ca. $210^{\circ} \mathrm{C}$ and $280{ }^{\circ} \mathrm{C}$ for ES250 and ES170 respectively. ES170 appears to follow a single stage exfoliation. In contrast, both the TMA and TGA curves in Figure 3A show that ES250 featured a two-stage exfoliation. The reason for this behaviour is not known at this stage. DSC results (not shown) indicated that the exfoliation, in both samples, is endothermic in nature.

Figure 4 shows TGA and DSC curves for the two intumescent flame retardants recorded in an air atmosphere. The DSC curve indicates that mass loss for the DAPAB occurred in four steps. The minor mass loss $(1 \%)$ below $200{ }^{\circ} \mathrm{C}$ probably reflects the loss of moisture. Starting at a temperature of about $225^{\circ} \mathrm{C}$, an event associated with a steep mass loss (ca. 16\%) occurred. This probably reflects the loss of $\mathrm{CO}_{2}$ due to the decarboxylation of the DABAP. The theoretical mass loss for decarboxylation is $17.6 \%$. Mass loss continued and next reached another peak value at a temperature of $465^{\circ} \mathrm{C}$. The DSC curve in Figure $4 \mathrm{~B}$ indicates that 
this reaction was exothermic whereas all the others mass loss steps were endothermic in nature. However, in a nitrogen atmosphere this step was endothermic probably because the char-forming decomposition reaction also released ammonia gas. The pyrolysis of the char continued as the temperature was raised. It reached a maximum rate at ca. $622{ }^{\circ} \mathrm{C}$ and was complete by about $750{ }^{\circ} \mathrm{C}$. The carbonized char residue that remained represented just above $2 \%$ of the initial DABAP mass.

The DSC curve (Figure 4A) indicates that the decomposition route for the EDAP was significantly more complicated. The melting and decomposition of this additive commences just above $200{ }^{\circ} \mathrm{C}$. It is characterized by two sharp DSC peaks located at ca. $225^{\circ} \mathrm{C}$ and 245 ${ }^{\circ} \mathrm{C}$. The first is attributed to the onset of melting and the second to an endothermic decomposition reaction. Multiple peaks are observed between $280{ }^{\circ} \mathrm{C}$ and $480{ }^{\circ} \mathrm{C}$. Their number and positions vary with each scan. This suggests that they are associated with the erratic release of gaseous products during the on-going char-forming decomposition reactions. The well-defined DTG peak located at ca. $615^{\circ} \mathrm{C}$ is associated with the air oxidation reaction. The DSC curve in Figure 4A indicates that this reaction is exothermic whereas all the others are endothermic in nature. The carbonized char residue remaining at $900{ }^{\circ} \mathrm{C}$ was only about $6 \%$.

\section{Cone calorimeter fire testing}

The cone calorimeter results are summarized in Table 1 and 2 and are presented in Figures 5 to 11. All the samples ignited and flamed for a short period of time. Table 2 lists the ignition and flame out times for the various samples. The time to ignition $\left(t_{\mathrm{ig}}\right)$ was $58 \pm 3 \mathrm{~s}$ for the neat polyethylene and $46 \pm 1 \mathrm{~s}$ for the compound containing $10 \mathrm{wt} . \%$ EG but decreased to 33 \pm 5 for the compound containing 27 wt. $\%$ DABAP. For other samples the addition of the 
flame retardants increased the propensity of the material to ignite. See Table 2 for other values. The times to ignition were shorter for the flame retarded compounds. This phenomenon is attributed to the lower thermal stability of the additives relative to the neat polymer and the destabilization of the polymer by the presence of the additives. Support for this contention was provided by thermogravimetric analysis results. (19) Addition of the flame retardants resulted in the initiation of mass loss at lower temperatures. This implies that flammable volatiles could have been released at an earlier stage in the fire tests.

The time to flame out showed considerable variability. It was $773 \pm 307 \mathrm{~s}$ for the neat polyethylene. It was longer for all flame retarded samples except for the $27 \mathrm{wt}$ \% DABAP compound where it was reduced to $539 \pm 69 \mathrm{~s}$.

The heat release curves for the black-pigmented polyethylene compound exhibited the shape characteristic of a thermally thin sample. (20) Thermally thin samples feature a sharp peak in their $H R R$ curves as the whole sample is pyrolyzed at once. $H R R$ curves characteristic of thermally thick, char-producing samples show a sudden rise to a plateau value. (20) The $H R R$ curves for the flame retarded samples approached this shape. They showed a rapid rise after ignition followed by a slower downward taper in the heat release rate. The $H R R$ curve for the 27 wt. \% DABAP compound showed a third phase where a faster decay in the heat release rate occurred. All the flame retarded samples expanded during the fire test but expansion was more pronounced in the samples containing EG.

Figure 5 shows representative heat release rate $(H R R)$ curves and Figure 6 reports peak heat release rates $(p H R R)$ obtained from the cone calorimeter tests. The $p H R R$ for the neat polyethylene was $710 \pm 109 \mathrm{~kW} \mathrm{~m}^{-2}$. Figure 5 and Table 1 shows that all $10 \mathrm{wt} . \% \mathrm{EG}$ compounds were more effective at reducing the pHRR than the 27 wt.\% DABAP compound. The 10 wt. $\%$ EG, 20 wt.\% DABAP compound reduced the $p H R R$ to $231 \pm 11 \mathrm{~kW} \mathrm{~m}^{-2}$. 
However, this is about the same as the value achieved by the compound with $10 \mathrm{wt} . \%$ ES250 alone. The best $p H R R$ reduction result was obtained with the $10 \mathrm{wt} . \%$ ES 250 plus $20 \mathrm{wt} . \%$ $\operatorname{EDAP}\left(187 \pm 1 \mathrm{~kW} \mathrm{~m}^{-2}\right)$ compound

Parameters that are pertinent to fire hazards are the fire load and flame spread. (20) The fire load is the total amount of heat that can be generated by a flammable material if it is ignited. In the cone calorimeter this index is quantified by the total heat released $(t H R)$. Rather unexpectedly the total heat release value measured was lowest for the carbon blackpigmented polyethylene at $90 \pm 18 \mathrm{MJ} \mathrm{m}^{-2}$. However, owing to the large uncertainty in the experimental $t H R$ values, the observed differences were not statistically significant. Flame spread is not directly measured in a cone calorimeter. The fire growth rate (FIGRA) and the fire growth index $\left(p H R R / t_{\mathrm{ig}}\right)$ proposed by Petrella $(21)$, can be used as proxy estimators for the flame spread (20). The FIGRA can usually be determined from the expression

FIGRA $=$ pHRR/time to $p H R R$

An important index used to interpret cone calorimeter data is the maximum average rate of heat emission $(M A H R E) .(20,22)$ The MAHRE parameter is defined as the peak value of the cumulative heat emission divided by time (22). It provides a measure of the propensity for fire development under full scale conditions. (22)

Table 1 lists the time to peak heat release rate together with the FIGRA, MAHRE and fire growth indices. For a material to be effectively flame retarded, the indices should all assume low values. Table 1 shows that all the flame retarded compounds did indeed achieve the required reductions relative to the neat carbon black pigmented polymer. The effect of composition on the MAHRE index is illustrated in Figure 7. The value for the reference 
compound was $317 \pm 47 \mathrm{~kW} \mathrm{~m}^{-2}$. The two intumescent flame retardants at $27 \mathrm{wt} . \%$ gave a marginal reduction. All other compounds showed a reduction in the MAHRE of more than $50 \%$ relative to the neat polyethylene. The best result was obtained with the $10 \mathrm{wt} . \%$ ES250 + 20 wt.\% DABAP combination.

The FIGRA data are plotted in Figure 8. The FIGRA value for the black pigmented polyethylene was $4.0 \pm 0.5 \mathrm{~kW} \mathrm{~m}^{-2} \mathrm{~s}^{-1}$. Using only DABAP or ES170 as flame retardants made very little difference to the value of this index. The ES250 EG grade was very effective in reducing the FIGRA but the best results were achieved with the $10 \mathrm{wt} . \% \mathrm{ES} 250+20 \mathrm{wt} . \%$ EDAP compound. The FIGRA for this combination was only $40 \%$ of the value for the reference compound.

Figure 9 and Table 1 show that, barring the two IFR additives at $27 \mathrm{wt} . \%$, all other flame retarded compounds decreased the $p H R R / t_{\text {ig }}$ parameter. The reason for the poor performance of the IFRs was their short ignition times (Table 2). These times were shortened in proportion to the degree of reduction in the peak heat release rates of said compounds. The lowest value for the fire growth index was $p H R R / t_{\mathrm{ig}}=5.1 \mathrm{~kW} \mathrm{~m}^{-2} \mathrm{~s}^{-1}$ while that for the neat polymer was 12 $1 \mathrm{~kW} \mathrm{~m} \mathrm{~s}^{-1}$. These were achieved by the $10 \mathrm{wt} . \%$ ES250 compound and the compound containing 10 wt. $\%$ ES250 + 20 wt.\% EDAP. As previously mentioned, both the fire growth rate (FIGRA) and the fire growth index $\left(p H R R / t_{\mathrm{ig}}\right)$ are considered to be potential estimators for the flame spread. (20) This implies that these two parameters should be linearly correlated. These two parameters are plotted against one another in Figure 9. If the reference polyethylene compound, and the compound containing $27 \mathrm{wt} \%$ DABAP, are not included, it reveals that the two parameters are correlated.

The improved fire performance, with respect to the various fire indices, is attributed to the formation of heat-insulating protective barriers at the solid surface exposed to the radiant heat. 
These layers limited heat transfer to the substrate and this slowed down the rate of thermal degradation of the polymer. This, in turn, reduced the rate at which volatile fuel was released. This means that less material was consumed during fire testing of the flame retarded samples. This is confirmed by the higher residue values listed in Table 2.

The smoke generated by fires reduces visibility and this can significantly affect life safety in underground mining applications. (23) Figure 10 compares the total smoke release (TSR) during the flaming phase of the cone calorimeter tests of the composites with that for the neat polyethylene. In general adding an intumescent flame retardant only lowered the peak smoke production rate but the total amount of smoke released increased significantly. The lowering of the peak amount is attributed to the surface barrier generated by intumescence which reduces the rate of combustion. The overall increase is attributed to the lower molar mass and consequently higher volatility of the intumescent flame retardants. The $27 \mathrm{wt} . \%$ DABAP compound produced the highest amount of smoke. This is possibly due to the aromatic nature of this compound which facilitates soot formation. All the compounds containing expandable graphite showed very similar performance with a considerable reduction in smoke generation. These results indicate that EGs are powerful suppressants of the smoke, including that produced by the intumescent additives. These observations may be explained as follows: the expanded graphite flakes do not decompose to contribute to smoke creation. Instead, the high surface area of the porous layer of exfoliated graphite "worms" formed at the top of the sample probably absorbs smoke particles emitted by the rest of the material.

In fire deaths the influence of heat is considered to be of minor importance. Mortality is invariably caused by toxic gases (17) in which carbon monoxide is the main culprit, with carbon dioxide of secondary importance. $(24,25)$ The observed trends for $\mathrm{CO}_{2}$ release rates mirrored those observed for the HRR (Figure 6) almost perfectly. However, Figure 11 shows that the measured $\mathrm{CO}$ release rate curves were more complex. Although the peak rate of $\mathrm{CO}$ 
release was higher for the neat polyethylene, the total amount produced by the intumescent additive containing compounds appeared to be slightly higher. However, the $\mathrm{CO}$ emissions were significantly lower with the two compounds containing $10 \mathrm{wt} . \% \mathrm{EG}$. This suggests that the decomposition of the EGs does not result in significant $\mathrm{CO}$ generation in comparison to the IFRs. In addition, the lower rate of fuel generation from the decomposition of the polymer may have resulted in a leaner flame and thus more complete combustion with lower carbon monoxide content in the exhaust gases.

Compositions containing EDAP as intumescent outperformed those containing DABAP in terms of the fire indices and the peak heat release rate. The EDAP formulations ignited later but still reached their peak heat release rate earlier but burned for a longer period of time. This was true irrespective of the expandable graphite used. In contrast to this, the opposite was true with respect to the mass of the char residue that remained following a cone test. In other words, comparable DABAP formulations showed a better char yield. Figure 12 shows FEGSEM micrographs of the microstructure of chars obtained by exposing 1:1 (mass basis) mixtures of ES250 with EDAP or DABAP after exposure to an open flame. These pictures should be compared with those in Figure 2 which show the uncoated accordion-like surface of the expanded "worms". Careful inspection of these and several other micrographs suggests that the EDAP did indeed form a more cohesive coating on the EG flake edges as they expanded together than DABAP did. The reason for the improved performance of the EDAP systems may therefore be found in the superior integrity of the intumescent char layer that formed at the surface of the test samples. Further confirmation was obtained by visual inspection of the cone calorimeter chars. These also indicated that EDAP as an IFR resulted in char residues with a greater cohesion. 


\section{Conclusions}

The effectiveness of two expandable graphite grades and two intumescent flame retardants was evaluated. Pressed sheets with a nominal thickness of $3.2 \mathrm{~mm}$ were tested in a cone calorimeter at a radiant flux of $35 \mathrm{~kW} \mathrm{~m}^{-2}$. A polyethylene compound pigmented black with 5 wt.\% carbon black was used as the reference material. The compositions of the flame retarded compounds were as follows: 0/27, 10/0, 10/10, and 10/20 wt.\% intumescent/expandable graphite. The peak heat release rate of the carbon black-pigmented polyethylene reference material was $710 \pm 109 \mathrm{~kW} \mathrm{~m}^{-2}$. All the flame retarded compounds significantly decreased the peak heat release rate. It was lowered to $231 \pm 7 \mathrm{~kW} \mathrm{~m}^{-2}$ and 230 $\pm 5 \mathrm{~kW} \mathrm{~m}{ }^{-2}$ in the presence of $10 \mathrm{wt} . \%$ expandable graphite with a low exfoliation onset temperature and 27 wt.\% ethylenediamine phosphate respectively. The lowest value was 187 $\pm 1 \mathrm{~kW} \mathrm{~m}{ }^{-2}$ obtained with a compound containing $10 \mathrm{wt} . \%$ expandable graphite and $20 \mathrm{wt} . \%$ ethylenediamine phosphate. The best char yield was obtained with compositions containing the high-decomposition- onset-temperature intumescent 3,5-diaminobenzoic acid phosphate. Despite this, the best fire performance was realized using the low-decomposition-onsettemperature ethylenediamine phosphate together with the low-exfoliation-onset-temperature expandable graphite. Formulations based on this intumescent compound also ignited later and reached the peak heat release rate earlier, but also burned for a longer time. This was true irrespective of the expandable graphite used. It is speculated that this can be attributed to the formation, at the burning surface, of a more cohesive char with better thermal and mass transport barrier properties. This would explain why compositions based on ethylenediamine phosphate as intumescent outperformed those containing 3,5-diaminobenzoic acid phosphate in terms of the peak heat release rate and other important fire indices. These results indicate that the low expansion onset temperature expandable graphite is most compatible with 
ethylenediamine phosphate, as the onset and mechanism of expansion and intumescence respectively are well matched between these compounds. Furthermore, it is surmised that all binary compounds studied showed synergistic fire behaviour, resulting in far superior fire behaviour compared to their individual flame retarded counterparts.

The intumescent additives increased the total smoke release and retained high $\mathrm{CO}$ production rates whereas with both the expandable graphite grades the emission of both was suppressed. This possibly indicates strong smoke suppressing potential in expandable graphite.

\section{Acknowledgements}

This work is based upon research supported by the South African Research Chairs Initiative of the Department of Science and Technology (DST) and the National Research Foundation (NRF). Any opinion, findings and conclusions or recommendations expressed in this material are those of the authors and therefore the NRF ad DST do not accept any liability with regard thereto.

\section{References}

1. Weil ED, Levchik SV. Flame retardants in commercial use or development for polyolefins. Journal of Fire Sciences. 2008;26(1):5-43.

2. Dasari A, Yu ZZ, Cai GP, Mai YW. Recent developments in the fire retardancy of polymeric materials. Progress in Polymer Science. 2013;38(9):1357-87.

3. Qu B, Xie R. Intumescent char structures and flame-retardant mechanism of expandable graphite-based halogen-free flame-retardant linear low density polyethylene blends. Polymer International. 2003;52(9):1415-22.

4. Xie R, Qu B. Expandable graphite systems for halogen-free flame-retarding of polyolefins. I. Flammability characterization and synergistic effect. Journal of Applied Polymer Science. 2001;80(8):1181-9.

5. Xie R, Qu B. Expandable graphite systems for halogen-free flame-retarding of polyolefins. II. Structures of intumescent char and flame-retardant mechanism. Journal of Applied Polymer Science. 2001;80(8):1190-7.

6. Pang $X Y$, Song M. Preparation and anti-flame capability of expandable graphite. Advanced Materials Research. 2012;560-561:779-83.

7. Sun Z, Ma Y, Xu Y, Chen X, Chen M, Yu J, et al. Effect of the particle size of expandable graphite on the thermal stability, flammability, and mechanical properties of high-density 
polyethylene/ethylene vinyl-acetate/expandable graphite composites. Polymer Engineering \& Science. 2014;54(5):1162-9.

8. Han Z, Dong L, Li Y, Zhao H. A Comparative Study on the Synergistic Effect of Expandable Graphite with APP and IFR in Polyethylene. Journal of Fire Sciences. 2007;25(1):79-91.

9. Camino G, Costa L, Martinasso G. Intumescent fire-retardant systems. Polymer Degradation and Stability. 1989;23(4):359-76.

10. Wang JQ, Chow WK. A brief review on fire retardants for polymeric foams. Journal of Applied Polymer Science. 2005;97(1):366-76.

11. Lewin M. Synergistic and catalytic effects in flame retardancy of polymeric materials - an overview. Journal of Fire Sciences. 1999;17(1):3-19.

12. Furdin G. Exfoliation process and elaboration of new carbonaceous materials. Fuel. 1998;77(6):479-85.

13. Camino G, Duquesne S, Delobel R, Eling B, Lindsay C, Roels T. Mechanism of Expandable Graphite Fire Retardant Action in Polyurethanes. Fire and Polymers. ACS Symposium Series. 797: American Chemical Society; 2001. p. 90-109.

14. Wissler M. Graphite and carbon powders for electrochemical applications. Journal of Power Sources. 2006;156(2):142-50.

15. Chung DDL. Exfoliation of graphite. Journal of Materials Science. 1987;22(12):4190-8.

16. Chung DDL. Review: Graphite. Journal of Materials Science. 2002;37(8):1475-89.

17. Babrauskas $V$, Peacock RD. Heat release rate: The single most important variable in fire hazard. Fire Safety Journal. 1992;18(3):255-72.

18. Focke WW, Kruger HJ, Mhike W, Taute A, Roberson A, Ofosu O. Polyethylene flame retarded with expandable graphite and a novel intumescent additive. Journal of Applied Polymer Science. 2014;131(13):n/a-n/a.

19. Focke WW, Badenhorst $\mathrm{H}$, Mhike W, Kruger HJ, Lombaard D. Characterization of commercial expandable graphite fire retardants. Thermochimica Acta. 2014;584(0):8-16.

20. Schartel B, Hull TR. Development of fire-retarded materials-Interpretation of cone calorimeter data. Fire and Materials. 2007;31(5):327-54.

21. Petrella RV. The Assessment of Full-Scale Fire Hazards from Cone Calorimeter Data. Journal of Fire Sciences. 1994;12:14-43.

22. Sacristán M, Hull TR, Stec AA, Ronda JC, Galià M, Cádiz V. Cone calorimetry studies of fire retardant soybean-oil-based copolymers containing silicon or boron: Comparison of additive and reactive approaches. Polymer Degradation and Stability. 2010;95(7):1269-74.

23. Perera I. E. and Litton CD, . . 10: . 10.3801/IAFSS.FSS.10-213. A Detailed Study of the Properties of Smoke Particles Produced from both Flaming and Non-Flaming Combustion of Common Mine Combustibles. Fire Safety Science: Fire Safety Science Digital Archive; 2011. p. 213-26.

24. Gormsen $\mathrm{H}$, Jeppesen $\mathrm{N}$, Lund $\mathrm{A}$. The causes of death in fire victims. Forensic science international. 1984;24(2):107-11.

25. Hirschler MM, editor Fire Retardance, Smoke Toxicity and Fire Hazard. Flame Retardants ' 94 British Plastics Federation; 1994; London: Interscience Communications.

\section{LIST OF TABLES}

Table 1. Cone calorimeter data summary for peak heat release rate $(p H R R)$, time to peak heat release rate $(t-P H R R), M A H R E, F I G R A$ and the fire growth index $\left(p H R R / t_{\text {ign }}\right)$. 
Table 2. Cone calorimeter data summary for time to ignition $\left(t_{\mathrm{ign}}\right)$, time to flame out $\left(t_{\mathrm{fo}}\right)$, total heat release $(T H R)$, residual mass, total smoke release $(T S R)$, and peak specific extinction area $(S E A)$.

\section{LIST OF FIGURES}

Figure 1. FEGSEM micrographs of the (A) ethylenediamine phosphate (EDAP) powder and (B) the diaminobenzoic acid phosphate crystals (DABAP).

Figure 2. Micrographs of the expanded graphite samples after exfoliation in the ESEM. (A) Low onset temperature EG (ES250 B5) and (B) high onset temperature EG (ES170 300A).

Figure 3. TGA (in air) and TMA (in nitrogen) curves for (A) the low exfoliation onset temperature EG (ES250) and (B) the high exfoliation onset temperature EG (ES170). In the TMA and TGA experiments the temperature was scanned to $600{ }^{\circ} \mathrm{C}$ and $900{ }^{\circ} \mathrm{C}$ respectively at a scan rate of $10{ }^{\circ} \mathrm{C} \mathrm{min}-1$ with gas flowing at a rate of $50 \mathrm{~mL} \mathrm{~min}{ }^{-1}$. In the TMA experiment, a flat-tipped standard expansion probe was used and the applied force was 0.005 N.

Figure 4. TGA (thick line) and DSC (thin red line) curves for (A) ethylenediamine phosphate (EDAP) and (B) 3,5-diaminobenzoic acid phosphate. Temperature was scanned to $900{ }^{\circ} \mathrm{C}$ at a scan rate of $10{ }^{\circ} \mathrm{C} \mathrm{min}^{-1}$ with air flowing at a rate of $50 \mathrm{~mL} \mathrm{~min}{ }^{-1}$. 
Figure 5. Cone calorimeter heat release rate curves for the various compounds. A. Low exfoliation onset temperature EG (ES250) with ethylenediamine phosphate (EDAP). B. ES250 with diaminobenzoic acid phosphate (DABAP). C. High exfoliation onset temperature expandable graphite (ES170) with EDAP. D. ES170 with DABAP. The sample sheets were backed by aluminium foil and their dimensions were $100 \mathrm{~mm} \times 100 \mathrm{~mm} \times 3.2 \pm$ $0.1 \mathrm{~mm}$. They were exposed horizontally to an external heat flux of $35 \mathrm{~kW} \mathrm{~m}$.

Figure 6. Cone calorimeter peak heat release rates for polyethylene flame retarded with different expandable graphite (EG) grades and intumescent flame retardants (IFR). The sample sheets were backed by aluminium foil and their dimensions were $100 \mathrm{~mm} \times 100 \mathrm{~mm}$ $\times 3.2 \pm 0.1 \mathrm{~mm}$. They were exposed horizontally to an external heat flux of $35 \mathrm{~kW} \mathrm{~m}^{-2}$.

Figure 7. Cone calorimeter $M A H R E$ for polyethylene flame retarded with different expandable graphite (EG) grades and intumescent flame retardants (IFR). The sample sheets were backed by aluminium foil and their dimensions were $100 \mathrm{~mm} \times 100 \mathrm{~mm} \times 3.2 \pm 0.1$ $\mathrm{mm}$. They were exposed horizontally to an external heat flux of $35 \mathrm{~kW} \mathrm{~m}{ }^{-2}$.

Figure 8. Cone calorimeter FIGRA for polyethylene flame retarded with different expandable graphite (EG) grades and intumescent flame retardants (IFR). The sample sheets were backed by aluminium foil and their dimensions were $100 \mathrm{~mm} \times 100 \mathrm{~mm} \times 3.2 \pm 0.1 \mathrm{~mm}$. They were exposed horizontally to an external heat flux of $35 \mathrm{~kW} \mathrm{~m}^{-2}$. 
Figure 9. Relationship between the $F I G R A$ and the $p H R R / t_{\text {ig }}$ index for the present flame retarded compounds.

Figure 10. Cone calorimeter total smoke release for polyethylene flame retarded with different expandable graphite (EG) grades and intumescent flame retardants (IFR). The sample sheets were backed by aluminium foil and their dimensions were $100 \mathrm{~mm} \times 100 \mathrm{~mm}$ $\times 3.2 \pm 0.1 \mathrm{~mm}$. They were exposed horizontally to an external heat flux of $35 \mathrm{~kW} \mathrm{~m}^{-2}$.

Figure 11. Cone calorimeter CO production curves for the various compounds. A. Low exfoliation onset temperature EG (ES250) with ethylenediamine phosphate (EDAP). B. ES250 with diaminobenzoic acid phosphate (DABAP). C. High exfoliation onset temperature expandable graphite (ES170) with EDAP. D. ES170 with DABAP. The sample sheets were backed by aluminium foil and their dimensions were $100 \mathrm{~mm} \times 100 \mathrm{~mm} \times 3.2 \pm$ $0.1 \mathrm{~mm}$. They were exposed horizontally to an external heat flux of $35 \mathrm{~kW} \mathrm{~m}$.

Figure 12. SEM micrographs of the expanded EG microstructures obtained by exposing 1:1 mass ration mixtures of ES250 with either (A) EDAP or (B) DABAP. 


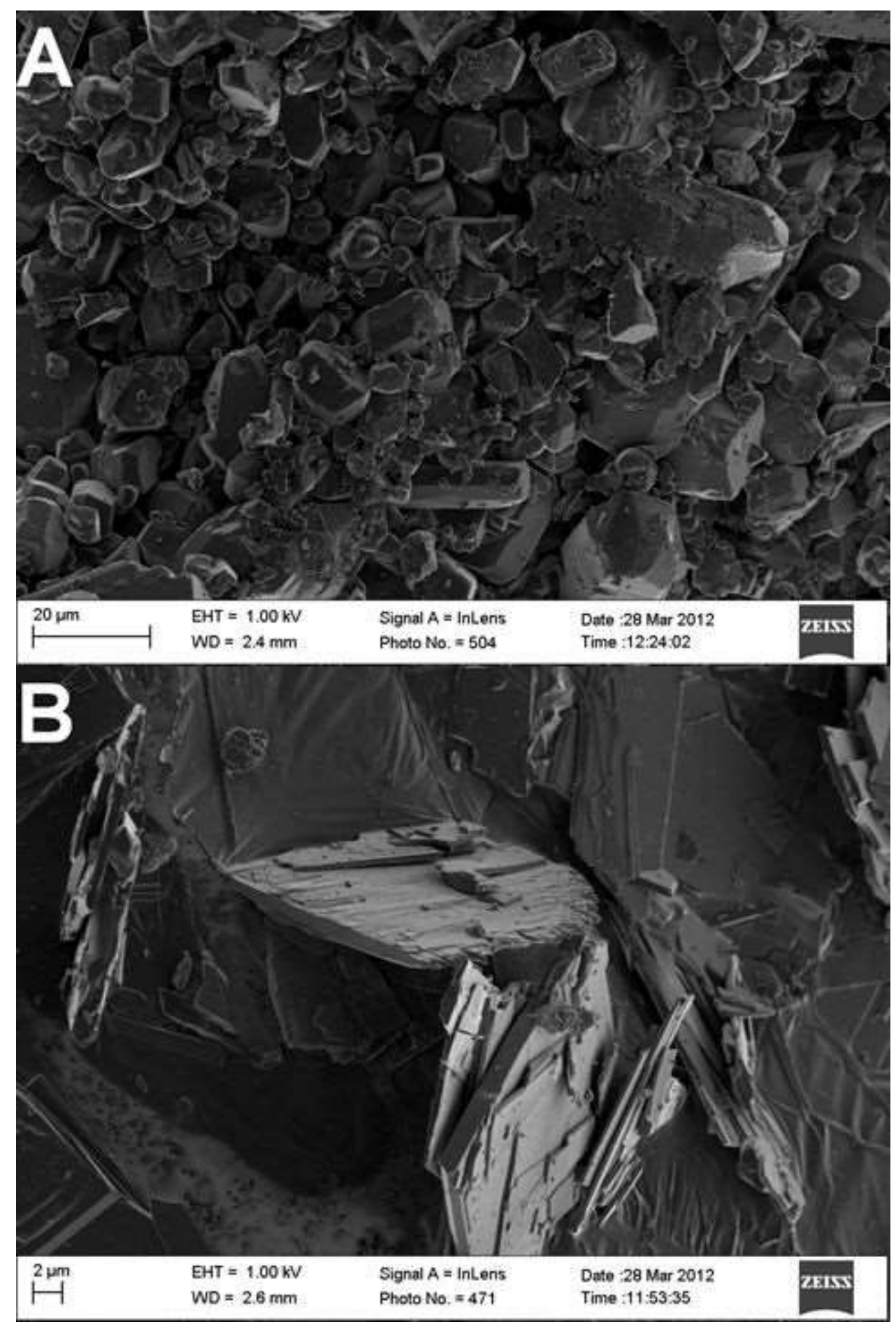

Figure 1. FEGSEM micrographs of the (A) ethylenediamine phosphate (EDAP) powder and (B) the diaminobenzoic acid phosphate crystals (DABAP). 


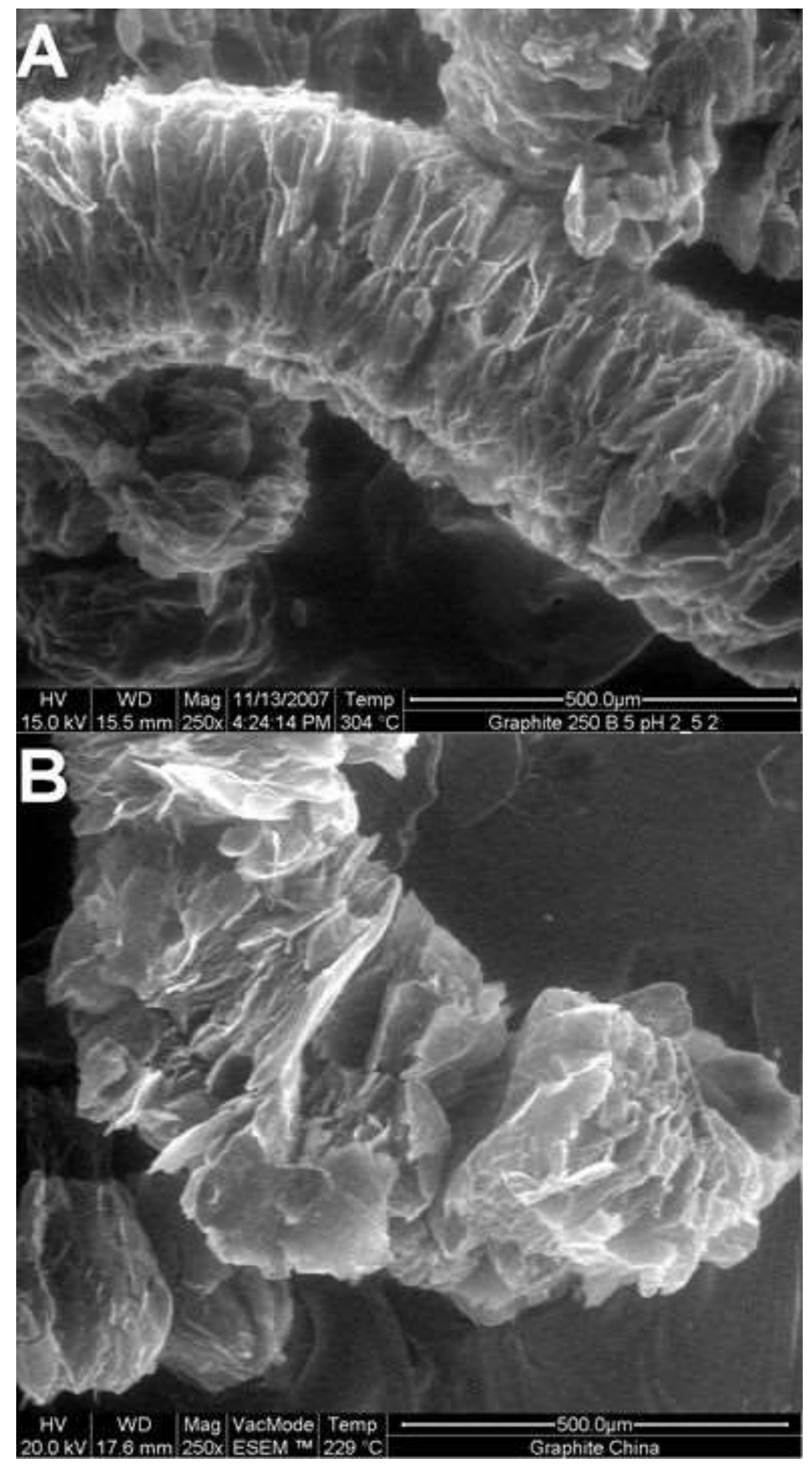

Figure 2. Micrographs of the expanded graphite samples after exfoliation in the ESEM. (A) Low onset temperature EG (ES250 B5) and (B) high onset temperature EG (ES170 300A). 

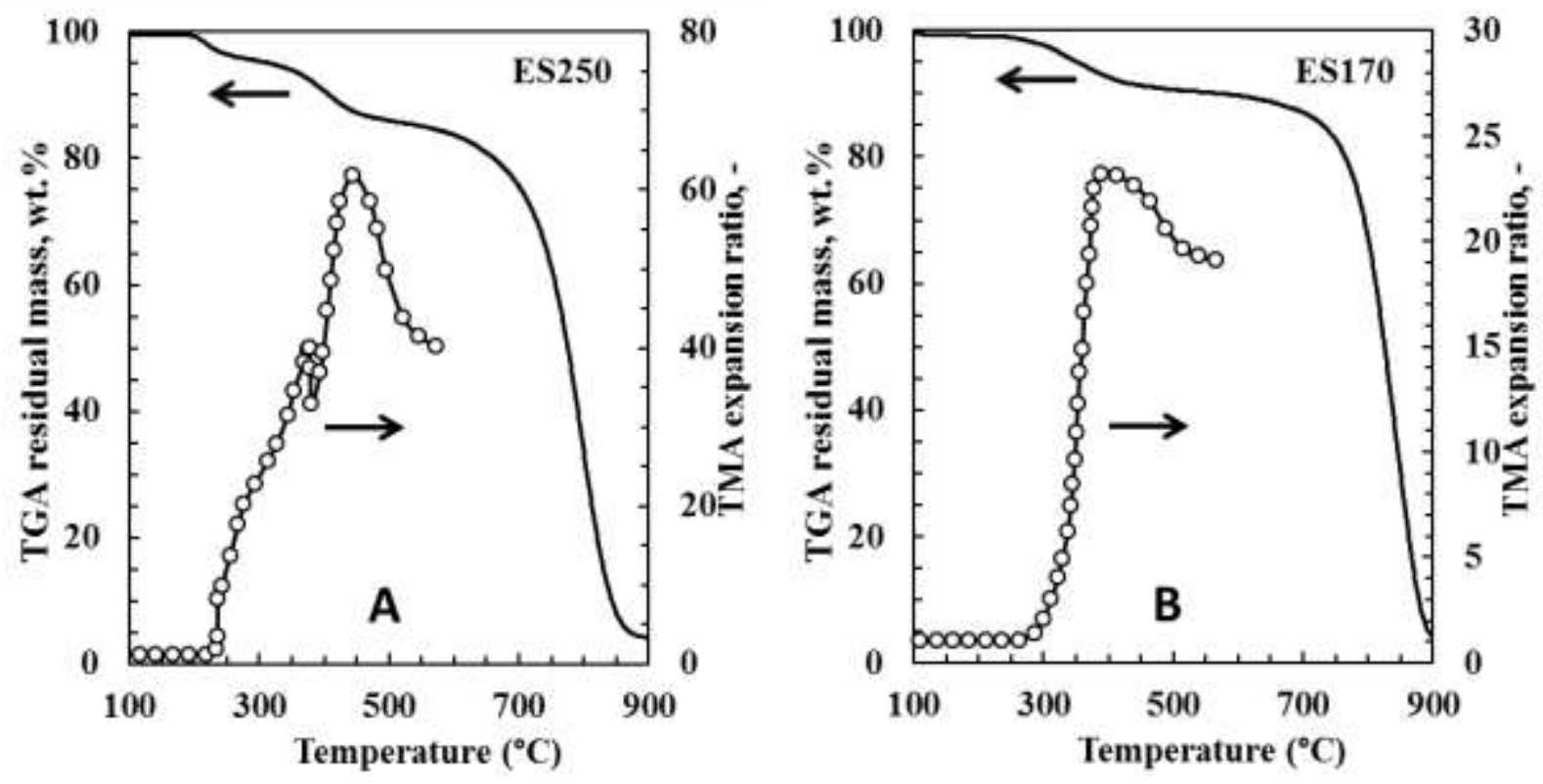

Figure 3. TGA (in air) and TMA (in nitrogen) curves for (A) the low exfoliation onset temperature EG (ES250) and (B) the high exfoliation onset temperature EG (ES170). In the TMA and TGA experiments the temperature was scanned to $600{ }^{\circ} \mathrm{C}$ and $900{ }^{\circ} \mathrm{C}$ respectively at a scan rate of $10{ }^{\circ} \mathrm{C} \mathrm{min}-1$ with gas flowing at a rate of $50 \mathrm{~mL} \mathrm{~min}^{-1}$. In the TMA experiment, a flat-tipped standard expansion probe was used and the applied force was 0.005 N. 

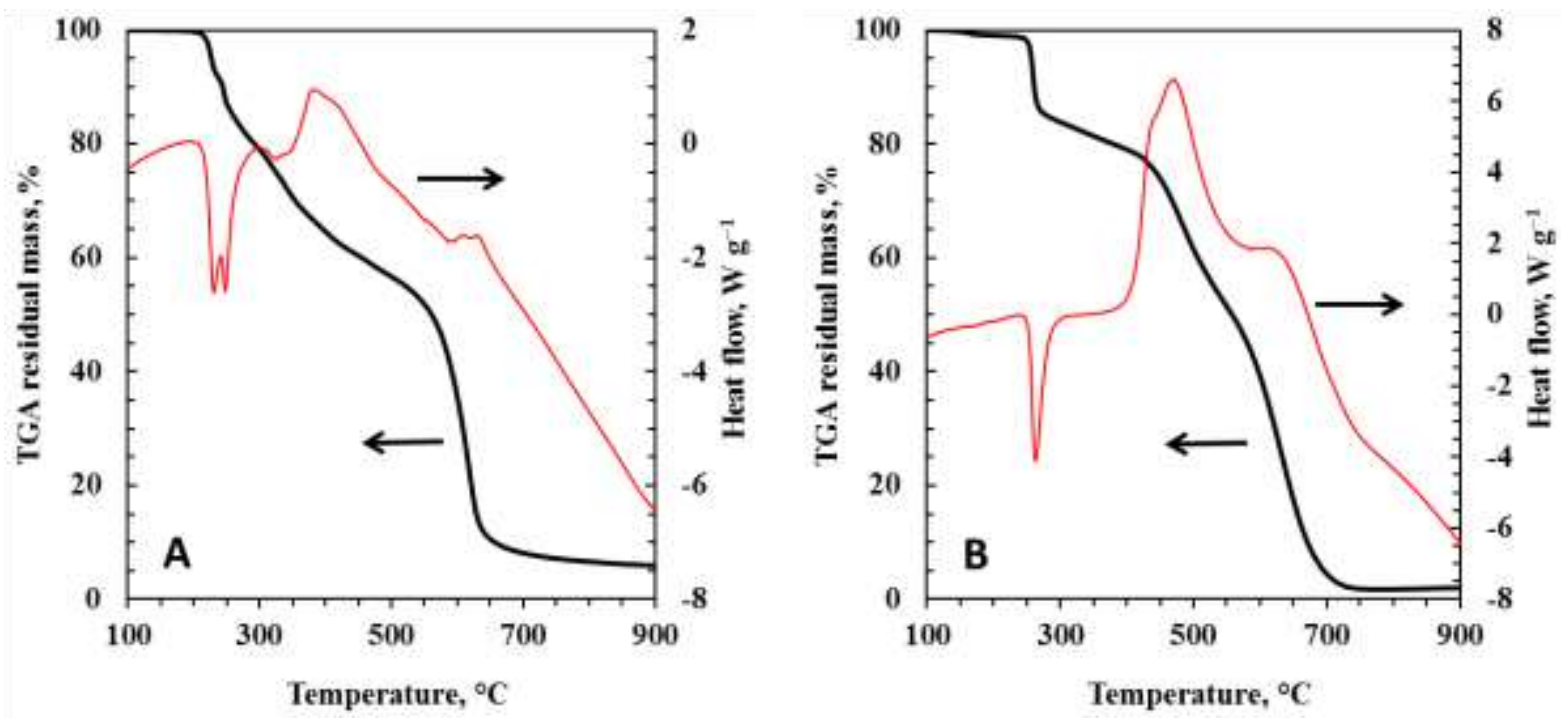

Figure 4. TGA (thick line) and DSC (thin red line) curves for (A) ethylenediamine phosphate (EDAP) and (B) 3,5-diaminobenzoic acid phosphate. Temperature was scanned to $900{ }^{\circ} \mathrm{C}$ at a scan rate of $10^{\circ} \mathrm{C} \mathrm{min}^{-1}$ with air flowing at a rate of $50 \mathrm{~mL} \mathrm{~min}$. 

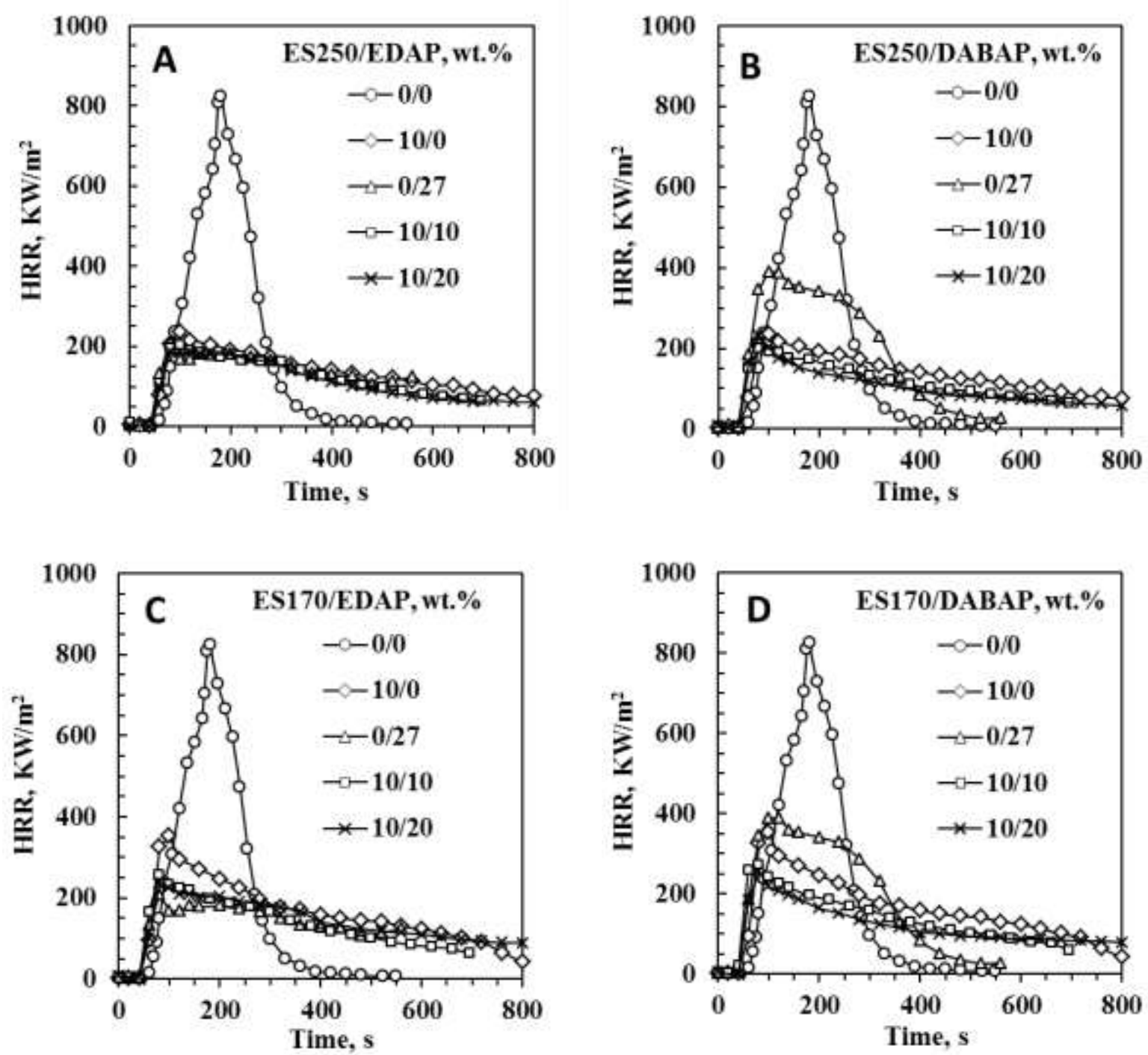

Figure 5. Cone calorimeter heat release rate curves for the various compounds. A. Low exfoliation onset temperature EG (ES250) with ethylenediamine phosphate (EDAP). B. ES250 with diaminobenzoic acid phosphate (DABAP). C. High exfoliation onset temperature expandable graphite (ES170) with EDAP. D. ES170 with DABAP. The sample sheets were backed by aluminium foil and their dimensions were $100 \mathrm{~mm} \times 100 \mathrm{~mm} \times 3.2 \pm$ $0.1 \mathrm{~mm}$. They were exposed horizontally to an external heat flux of $35 \mathrm{~kW} \mathrm{~m}^{-2}$. 


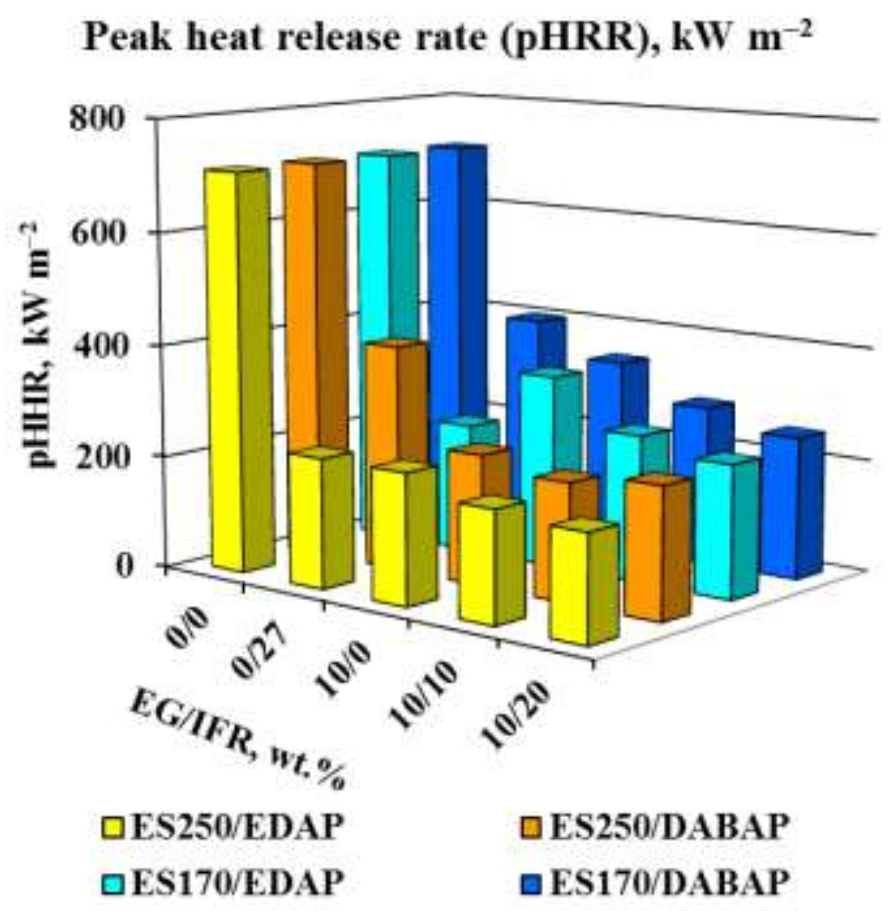

Figure 6. Cone calorimeter peak heat release rates for polyethylene flame retarded with different expandable graphite (EG) grades and intumescent flame retardants (IFR). The sample sheets were backed by aluminium foil and their dimensions were $100 \mathrm{~mm} \times 100 \mathrm{~mm}$ $\times 3.2 \pm 0.1 \mathrm{~mm}$. They were exposed horizontally to an external heat flux of $35 \mathrm{~kW} \mathrm{~m}^{-2}$. 


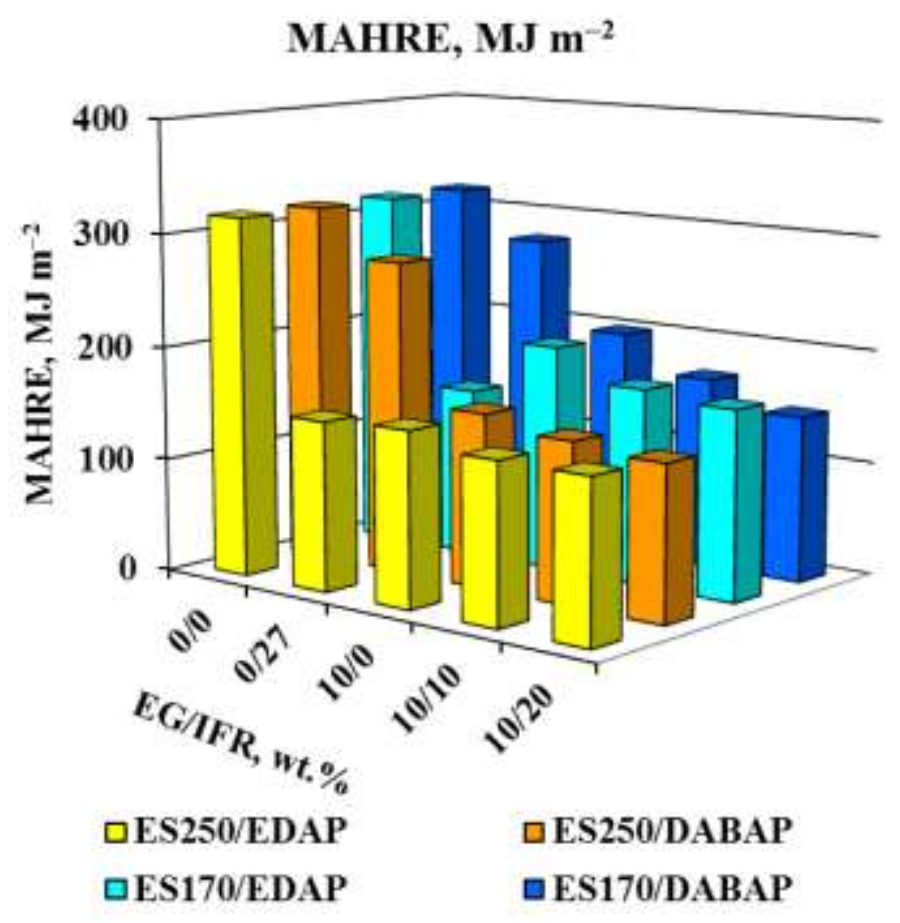

Figure 7. Cone calorimeter MAHRE for polyethylene flame retarded with different expandable graphite (EG) grades and intumescent flame retardants (IFR). The sample sheets were backed by aluminium foil and their dimensions were $100 \mathrm{~mm} \times 100 \mathrm{~mm} \times 3.2 \pm 0.1$ $\mathrm{mm}$. They were exposed horizontally to an external heat flux of $35 \mathrm{~kW} \mathrm{~m}{ }^{-2}$. 


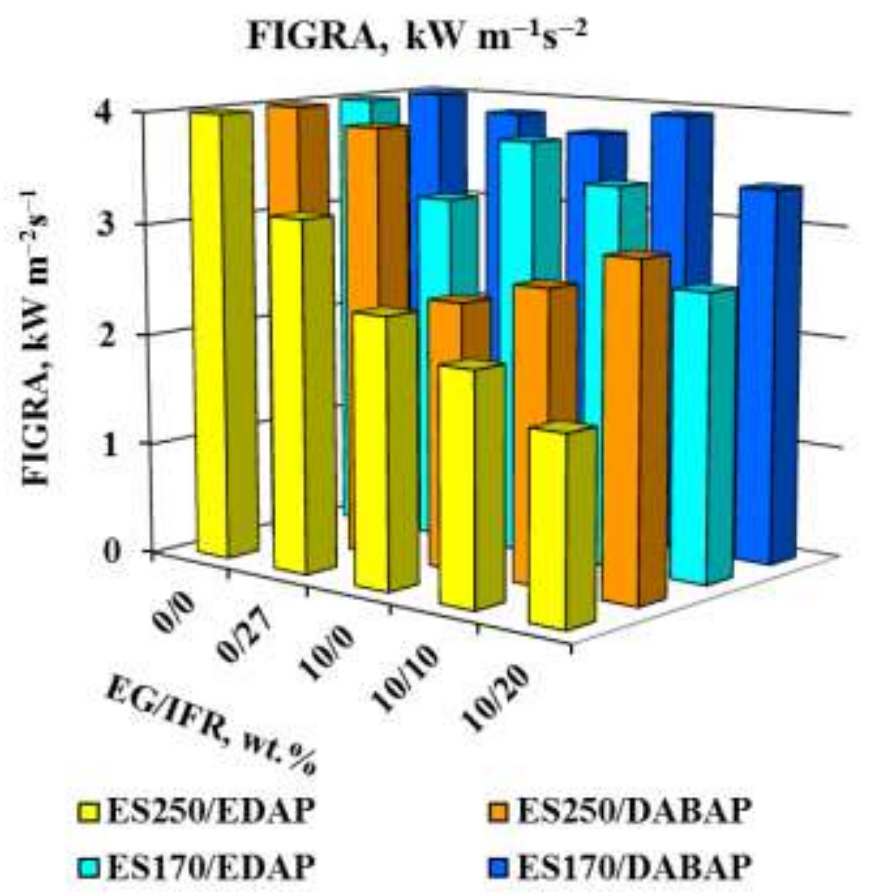

Figure 8. Cone calorimeter FIGRA for polyethylene flame retarded with different expandable graphite (EG) grades and intumescent flame retardants (IFR). The sample sheets were backed by aluminium foil and their dimensions were $100 \mathrm{~mm} \times 100 \mathrm{~mm} \times 3.2 \pm 0.1 \mathrm{~mm}$. They were exposed horizontally to an external heat flux of $35 \mathrm{~kW} \mathrm{~m}^{-2}$. 


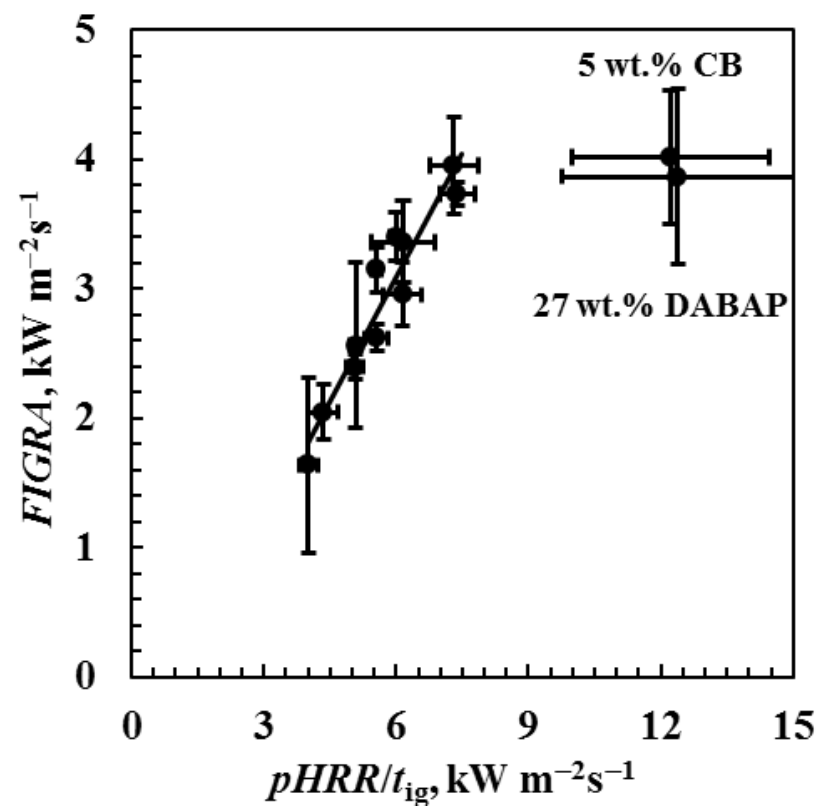

Figure 9. Relationship between the $F I G R A$ and the $p H R R / t_{\text {ig }}$ index for the present flame retarded compounds. 


\section{Total smoke release: TSR $\times 10^{-3}, \mathrm{~m}^{2} \mathrm{~m}^{-2}$}

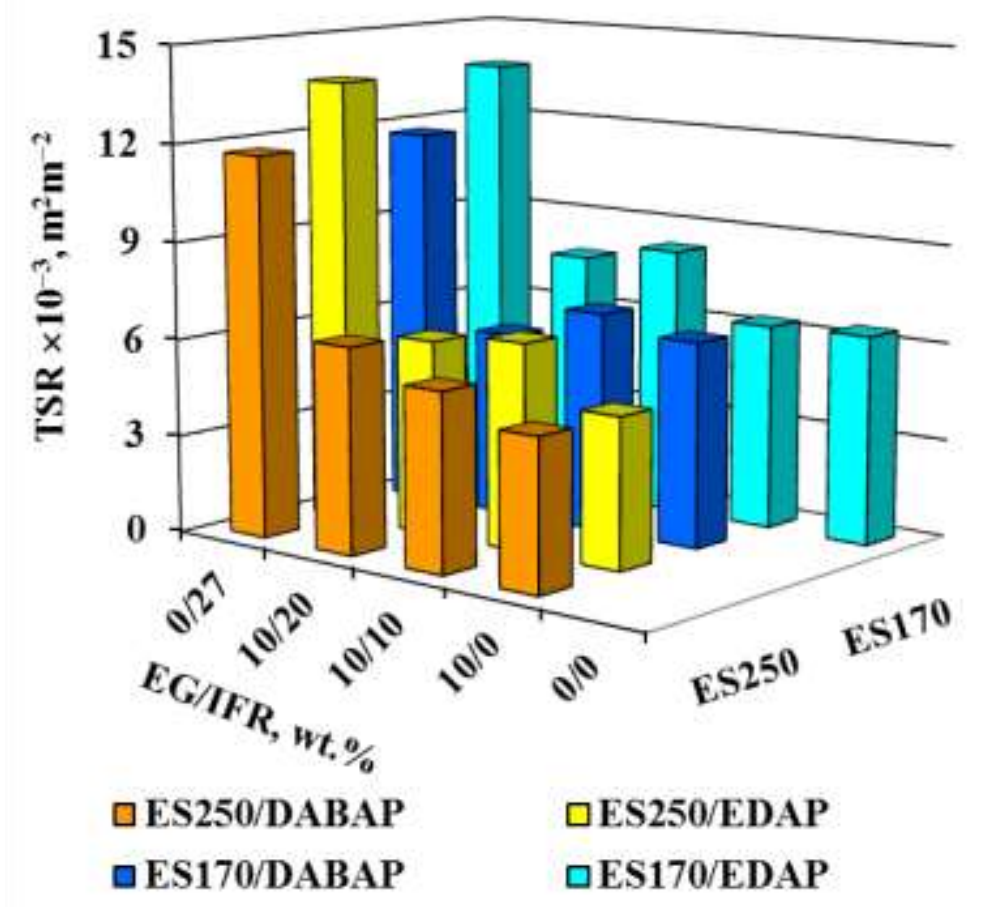

Figure 10. Cone calorimeter total smoke release for polyethylene flame retarded with different expandable graphite (EG) grades and intumescent flame retardants (IFR). The sample sheets were backed by aluminium foil and their dimensions were $100 \mathrm{~mm} \times 100 \mathrm{~mm}$ $\times 3.2 \pm 0.1 \mathrm{~mm}$. They were exposed horizontally to an external heat flux of $35 \mathrm{~kW} \mathrm{~m}^{-2}$. 

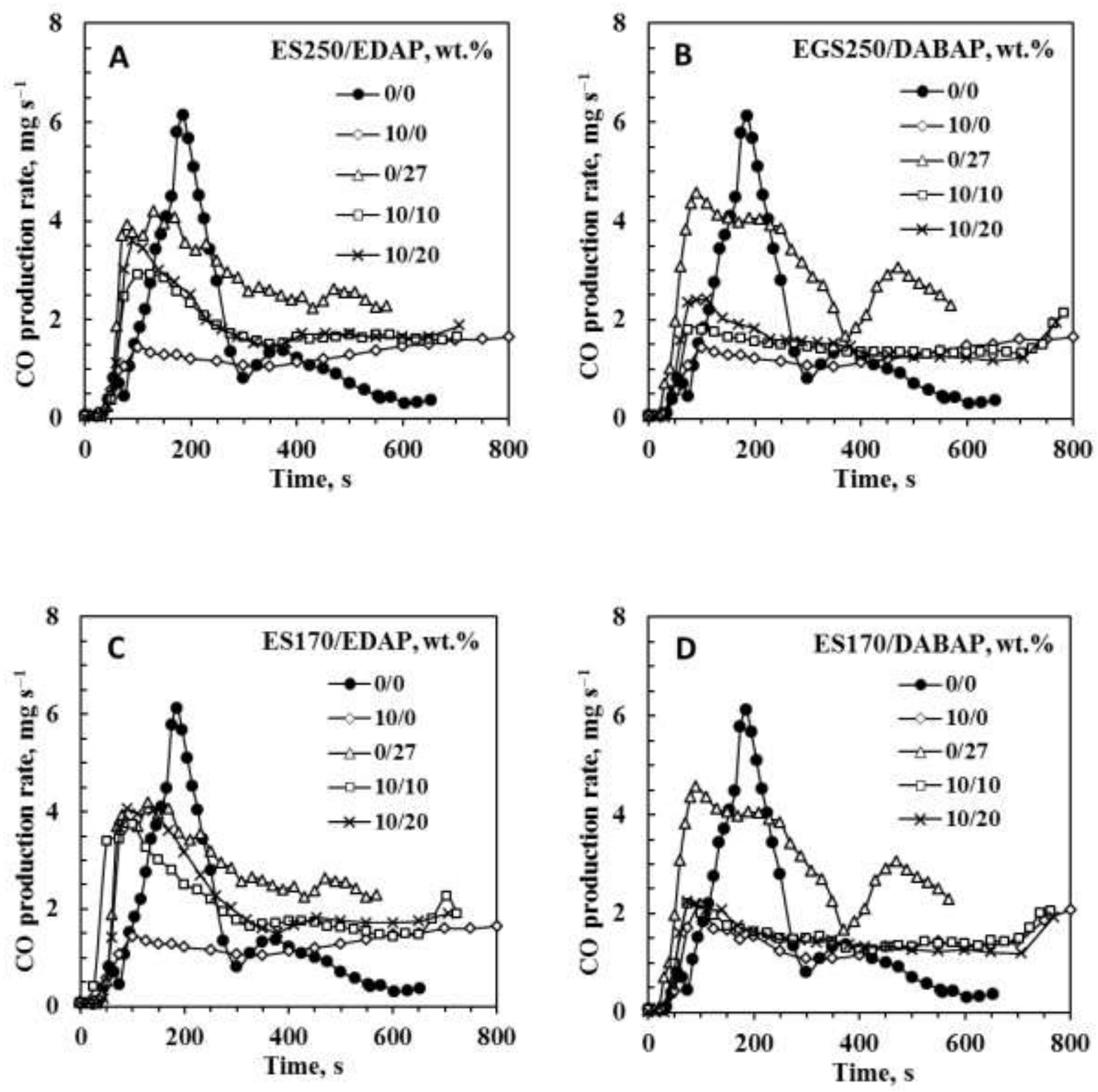

Figure 11. Cone calorimeter $\mathrm{CO}$ production curves for the various compounds. A. Low exfoliation onset temperature EG (ES250) with ethylenediamine phosphate (EDAP). B. ES250 with diaminobenzoic acid phosphate (DABAP). C. High exfoliation onset temperature expandable graphite (ES170) with EDAP. D. ES170 with DABAP. The sample sheets were backed by aluminium foil and their dimensions were $100 \mathrm{~mm} \times 100 \mathrm{~mm} \times 3.2 \pm$ $0.1 \mathrm{~mm}$. They were exposed horizontally to an external heat flux of $35 \mathrm{~kW} \mathrm{~m}{ }^{-2}$. 


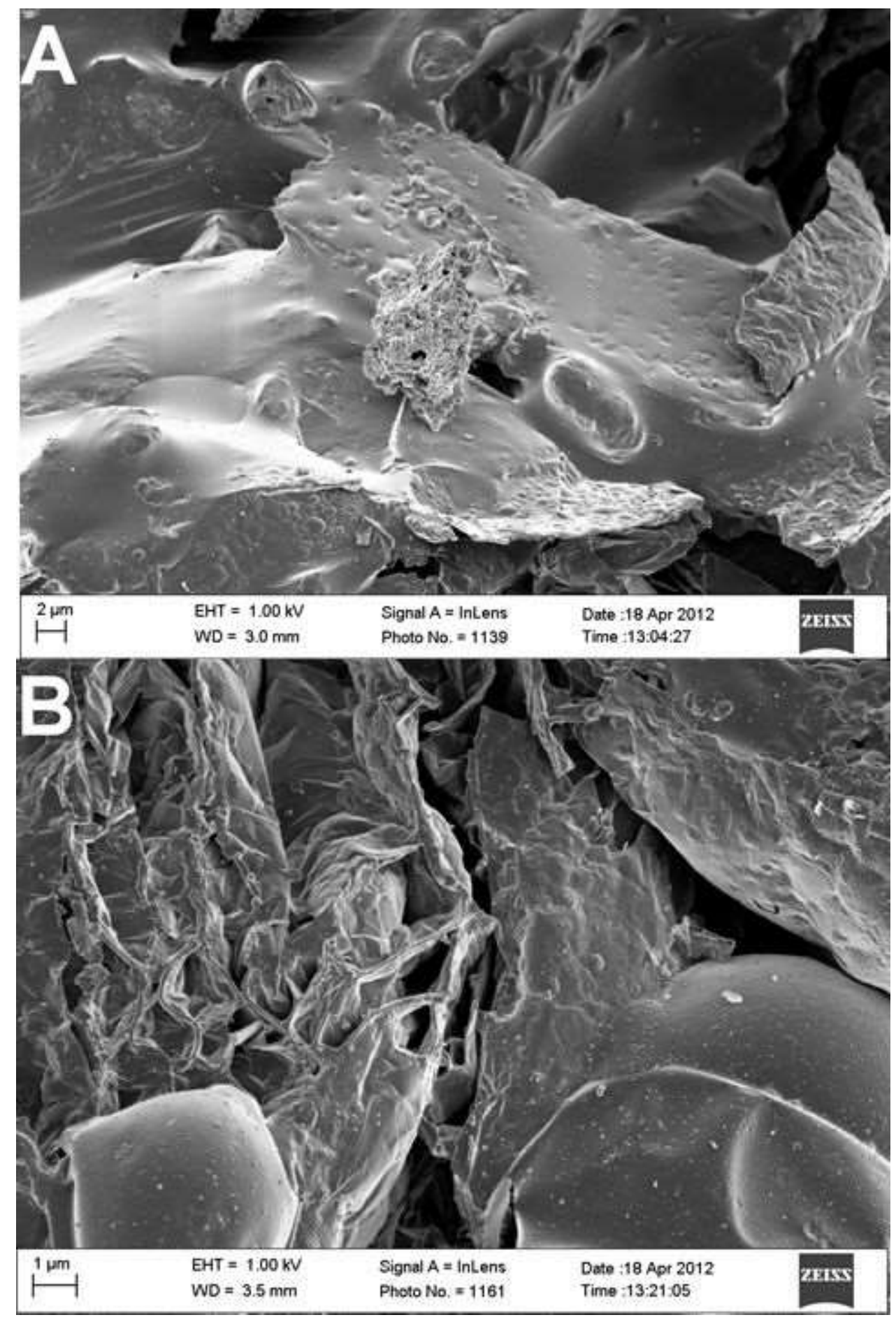

Figure 12. SEM micrographs of the expanded EG microstructures obtained by exposing 1:1 mass ration mixtures of ES250 with either (A) EDAP or (B) DABAP. 
Table 1. Cone calorimeter data summary for peak heat release rate $(p H R R)$, time to peak heat release rate $(t-P H R R), M A H R E, F I G R A$ and the fire growth index $\left(p H R R / t_{\text {ign }}\right)$.

\begin{tabular}{|c|c|c|c|c|c|}
\hline $\begin{array}{l}\text { Quantity } \\
\text { Sample (Composition) }\end{array}$ & $\begin{array}{l}\text { pHRR } \\
\mathrm{kW} \mathrm{m} \mathrm{m}^{-2}\end{array}$ & $\begin{array}{l}t-p H R R \\
\mathrm{~s}\end{array}$ & 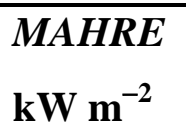 & $\begin{array}{l}\text { FIGRA } \\
\mathrm{kW} \mathrm{m}^{-2} \mathrm{~s}^{-1}\end{array}$ & $\begin{array}{l}p H R R / t_{\text {ign }} \\
\mathrm{kW} \mathrm{m}^{-2} \mathrm{~s}^{-1}\end{array}$ \\
\hline Polyethylene (5 wt.\% CB) & $710 \pm 109$ & $177 \pm 6$ & $317 \pm 47$ & $4.0 \pm 0.5$ & $12 \pm 2$ \\
\hline ES250 (10 wt.\%) & $231 \pm 7$ & $97 \pm 3$ & $154 \pm 6$ & $2.4 \pm 0.1$ & $5.1 \pm 0.2$ \\
\hline ES170 (10 wt.\%) & $342 \pm 15$ & $92 \pm 3$ & $199 \pm 13$ & $3.7 \pm 0.1$ & $7.4 \pm 0.4$ \\
\hline EDAP (27 wt.\%) & $230 \pm 5$ & $73 \pm 3$ & $149 \pm 6$ & $3.1 \pm 0.2$ & $12 \pm 3$ \\
\hline DABAP (27 wt.\% & $400 \pm 16$ & $105 \pm 13$ & $276 \pm 12$ & $3.9 \pm 0.7$ & $12 \pm 3$ \\
\hline ES250/EDAP (10/10 wt.\%) & $197 \pm 10$ & $97 \pm 8$ & $141 \pm 1$ & $2.1 \pm 0.2$ & $5.6 \pm 0.3$ \\
\hline ES250/DABAP (10/10 wt.\%) & $209 \pm 8$ & $80 \pm 0$ & $142 \pm 6$ & $2.6 \pm 0.1$ & $5.6 \pm 0.3$ \\
\hline ES170/EDAP (10/10 wt.\%) & $260 \pm 6$ & $77 \pm 3$ & $173 \pm 6$ & $3.4 \pm 0.2$ & $6.0 \pm 0.2$ \\
\hline ES170/DABAP (10/10 wt.\%) & $282 \pm 3$ & $72 \pm 6$ & $168 \pm 6$ & $4.0 \pm 0.4$ & $7.3 \pm 0.6$ \\
\hline ES250/EDAP (10/20 wt.\%) & $187 \pm 1$ & $128 \pm 53$ & $141 \pm 2$ & $1.6 \pm 0.7$ & $6.1 \pm 0.4$ \\
\hline ES250/DABAP (10/20 wt.\%) & $231 \pm 11$ & $78 \pm 3$ & $136 \pm 3$ & $3.0 \pm 0.2$ & $6.1 \pm 0.4$ \\
\hline ES170/EDAP (10/20 wt.\%) & $235 \pm 2$ & $97 \pm 29$ & $167 \pm 1$ & $2.6 \pm 0.6$ & $5.1 \pm 0.1$ \\
\hline ES170/DABAP (10/20 wt.\%) & $252 \pm 24$ & $75 \pm 0$ & $146 \pm 7$ & $3.4 \pm 0.3$ & $6.2 \pm 0.7$ \\
\hline
\end{tabular}


Table 2. Cone calorimeter data summary for time to ignition $\left(t_{\mathrm{ign}}\right)$, time to flame out $\left(t_{\mathrm{fo}}\right)$, total heat release $(T H R)$, residual mass, total smoke release $(T S R)$, and peak specific extinction area (SEA).

\begin{tabular}{|c|c|c|c|c|c|c|}
\hline & $\begin{array}{l}t_{\text {ign }} \\
\mathrm{S}\end{array}$ & $\begin{array}{l}\mathbf{t}_{\text {fo }} \\
\mathrm{S}\end{array}$ & $\begin{array}{l}\text { THR } \\
\mathrm{MJ} / \mathrm{m}^{2}\end{array}$ & $\begin{array}{l}\text { Residue } \\
\text { wt.\% }\end{array}$ & $\begin{array}{l}T S R \times 10^{-3} \\
\mathrm{~m}^{2} / \mathrm{m}^{2}\end{array}$ & $\begin{array}{l}\text { Peak } S E A \times 10^{-3} \\
\mathrm{~m}^{2} / \mathrm{kg}\end{array}$ \\
\hline Polyethylene (5 wt.\% CB) & $58.3 \pm 2.5$ & $773 \pm 307$ & $90 \pm 18$ & $8.3 \pm 3.2$ & $0.73 \pm 0.14$ & $1.6 \pm 1.4$ \\
\hline ES250 (10 wt.\%) & $45.7 \pm 1.5$ & $1049 \pm 12$ & $119 \pm 14$ & $18.5 \pm 0.3$ & $0.53 \pm 0.01$ & $1.6 \pm 1.0$ \\
\hline ES170 (10 wt.\%) & $46.3 \pm 0.6$ & $869 \pm 68$ & $130 \pm 15$ & $12.8 \pm 0.1$ & $0.71 \pm 0.05$ & $1.7 \pm 0.5$ \\
\hline EDAP (27 wt.\%) & $41.3 \pm 0.6$ & $878 \pm 190$ & $103 \pm 8$ & $26.1 \pm 2.7$ & $1.45 \pm 0.19$ & $4.0 \pm 0.9$ \\
\hline DABAP (27 wt.\%) & $33.0 \pm 5.2$ & $537 \pm 69$ & $103 \pm 3$ & $22.4 \pm 0.5$ & $1.33 \pm 0.03$ & $1.8 \pm 0.9$ \\
\hline ES250/EDAP (10/10 wt.\%) & $45.3 \pm 1.2$ & $1046 \pm 17$ & $109 \pm 12$ & $26.3 \pm 0.4$ & $0.72 \pm 0.01$ & $1.5 \pm 0.3$ \\
\hline ES250/DABAP (10/10 wt.\%) & $37.7 \pm 0.6$ & $1172 \pm 48$ & $117 \pm 17$ & $27.8 \pm 0.4$ & $0.62 \pm 0.02$ & $3.5 \pm 1.1$ \\
\hline ES170/EDAP (10/10 wt.\%) & $43.3 \pm 1.2$ & $878 \pm 48$ & $105 \pm 3$ & $21.8 \pm 0.3$ & $0.94 \pm 0.07$ & $3.6 \pm 0.9$ \\
\hline ES170/DABAP (10/10 wt.\%) & $38.7 \pm 2.5$ & $993 \pm 46$ & $109 \pm 7$ & $23.4 \pm 1.6$ & $0.77 \pm 0.04$ & $1.5 \pm 0.7$ \\
\hline ES250/EDAP (10/20 wt.\%) & $46.7 \pm 2.5$ & $948 \pm 20$ & $100 \pm 9$ & $29.5 \pm 1.0$ & $0.68 \pm 0.02$ & $1.3 \pm 0.3$ \\
\hline ES250/DABAP (10/20 wt.\%) & $37.7 \pm 1.5$ & $1138 \pm 24$ & $99 \pm 10$ & $30.6 \pm 1.3$ & $0.72 \pm 0.06$ & $2.1 \pm 1.8$ \\
\hline ES170/EDAP (10/20 wt.\%) & $46.3 \pm 1.5$ & $866 \pm 28$ & $109 \pm 12$ & $26.6 \pm 1.0$ & $0.88 \pm 0.09$ & $2.5 \pm 1.0$ \\
\hline ES170/DABAP (10/20 wt.\%) & $41.0 \pm 1.0$ & $1124 \pm 106$ & $102 \pm 10$ & $31.6 \pm 2.1$ & $0.65 \pm 0.02$ & $3.2 \pm 1.3$ \\
\hline
\end{tabular}

